\title{
HARAPAN PADA LANSIA DENGAN DIABETES MELITUS TIPE 2
}

\author{
Lailatuz Zulia Ifianti, Rita Hadi Widyastuti \\ Ilmu Keperawatan, Fakultas Kedokteran Universitas Diponegoro \\ Jl. Prof. Sudarto No.13, Tembalang, Kec. Tembalang, Kota Semarang \\ Email: lailatuz31@gmail.com
}

\begin{abstract}
ABSTRAK
Diabetes melitus adalah gangguan metabolik yang ditandai dengan kenaikan kadar glukosa dalam darah dan dapat menyebabkan berbagai macam komplikasi sehingga mempengaruhi kualitas hidup lansia. Harapan akan membawa kepada keoptimisan dan meningkatkan kualitas hidup lansia dengan penyakit kronis. Sementara penelitian mengenai dampak harapan masih sangat kurang. Penelitian ini bertujuan untuk mendeskripsikan derajat harapan pada lansia dengan diabetes melitus tipe 2.Penelitian ini menggunakan desain penelitian kuantitatif survei, responden terdiri dari 127 lansia yang menderita DM tipe 2 yang diambil dengan teknik total sampling setelah memenuhi kriteria inklusi. Kuesioner HHI (Herth Hope Index) digunakan untuk mengetahui gambaran harapan. Uji validitas dan reliabilitas telah dilakukan dan hasilnya valid serta reliabel. Hasil penelitian ini menunjukkan bahwa karakteristik responden adalah didominasi usia 60-74 tahun, sebagian besar berjenis kelamin wanita, tingkat pendidikan didominasi oleh pendidikan SD-SMP, sebagian besar menikah, Suku Jawa, menderita DM < 5 tahun dan tidak mengalami komplikasi. Derajat harapan menunjukkan bahwa responden mempunyai harapan yang tinggi dengan nilai mean sebesar 37.41. Sebagian besar responden merasa hidupnya memiliki nilai dan berharga.Masyarakat dan petugas kesehatan harus membantu lansia mempertahankan derajat harapan yang sudah tinggi dengan menyediakan dukungan sosial dan membantu lansia mencari jalan keluar ketika menghadapi masalah tentang kesehatan dan yang lainnya.
\end{abstract}

Kata Kunci: diabetes mellitus; harapan; lansia

\section{HOPE IN ELDERLY WITH DIABETESMELLITUS TYPE 2}

\begin{abstract}
Diabetes mellitus is a metabolic disorder that signed with the increase of glucose level in blood and can make various complication which influences the elderly's quality of life. Hope will bring the optimism and increased the quality of life on elderly with chronic diseases. However, research supporting this effect is lacking. This study was aimed to find out the description of the hope level among elderly with diabetes mellitus type 2. This study was quantitative descriptive with 127 elderly diabetic patients taken by using total sampling technique by fulfilling the inclusion criteria. Herth Hope Index (HHI) questionnaire was used. The validity and reliability was confirmed. The results of this research show that the age of respondent was dominated with 60-74 years old, mostly consist of female. The education level was mostly elementary school, mostly have been married and from Javanese family, suffered from DM for about 5 years and mostly didn't have complications. For the hope level, the respondent mostly is in high level with mean score is 37.41. The respondent feel that their life is worth and precious. Based on the results of this research, the society and health center member should help the elderly to maintenance their level of hope by give the support system to the elderly and facilitate the elderly to solve their problem about health or another.
\end{abstract}

Keywords: diabetes mellitus; elderly; hope

Jurnal SMART Keperawatan is licensed under a Creative Commons Attribution-ShareAlike 4.0 International License. 


\section{LATAR BELAKANG}

Diabetes mellitus (DM) merupakan penyakit gangguan metabolik yang ditandai dengan kenaikan kadar glukosa darah yang disebabkan karena kelainan sekresi atau kerja insulin atau keduanya dan dapat menimbulkan berbagai komplikasi kronik (Matzinger, 2017).Prevalensi DM secara global pada tahun 2017 sebesar 425 juta orang dan diperkirakan akan naik sebesar 48\% (629 juta) pada 2045 (IDF,2017).

DM menjadi penyakit tidak menular (PTM) tertinggi ke-2 di Kota Semarang pada tahun 2017 (Dinkes, 2018). DM tidak dapat disembuhkan namun hanya dapat dikontrol agar kadar glukosa tetap stabil sehingga memerlukan perawatan jangka panjang.Penderita DM berisiko mengalami depresi 2 kali lebih besar dan meningkatkan angka kematian sebanyak 30\%(Harista, 2015). Harapan akan membawa lansia kepada keoptimisan sehingga meningkatkan kualitas hidup. Lansia dengan harapan rendah akan mengalami keputusasaan, pesimis dan kehilangan kontrol diri (Duggleby et al, 2013).

Menjaga harapan saat menghadapi penyakit kronis adalah sebuah koping stress dan dapat mendatangkan penerimaan terhadap krisis, meningkatkan pencapaian kepada derajat kesehatan yang lebih tinggi (Mauk,2004). Oleh karena itu pengukuran harapan pada lansia dengan DM sangat penting dilakukan. Penelitian ini bertujuan untuk mengetahui gambaran harapan pada lansia dengan DM tipe 2 yang berada di wilayah kerja puskesmas Kedungmundu Kota Semarang sebagai puskesmas dengan kasus DM tertinggi di Kota Semarang.

\section{METODE}

Jenis penelitian ini adalah penelitian kuantitatif deskriptif dengan metode survei. Teknik pengambilan sampel yang digunakan adalah teknik total sampling. Jumlah sampel sebesar 127 responden. Penelitian dilaksanakan di wilayah kerja Puskesmas Kedungmundu pada bulan April-Mei 2019. Pengumpulan data menggunakan kuesioner Herth Hope Index $(\mathrm{HHI})$ dari Kaye Herth dengan 12 item pertanyaan dan telah diterjemahkan kedalam bahasa Indonesia serta diuji validitas dan reliabilitas oleh peneliti dengan hasil valid dan reliabel. Analisis data menggunakan analisis univariat. Penelitian ini disetujui oleh Komisi Etik Penelitian Kesehatan Fakultas Kesehatan Masyarakat Universitas Diponegoro dengan No. 27/EA/KEPK-FKM/2018

\section{HASIL}

Karakteristik dan Nilai Harapan Lansia dengan Diabetes Melitus Tipe 2 di Wilayah Kerja Puskesmas Kedungmundu Kota Semarang

Tabel 1 menunjukkan bahwa mayoritas responden berusia 60-74 tahun (92.1\%) memiliki harapan sebesar 37.5. Pekerjaan responden mayoritas ibu rumah tangga (51.2\%) dengan harapan sebesar 37.2. Pendidikan responden $54.3 \%$ adalah SD-SMP dan memiliki nilai harapan 37.6, agama responden mayoritas islam yaitu $87.4 \%$ dan mempunyai nilai harapan sebesar 37.4, mayoritas masih memiliki pasangan (menikah) yaitu sebanyak $59.1 \%$ dan mempunyai nilai harapan sebesar 38.0 , jenis kelamin didominasi oleh perempuan yaitu sebanyak $72.4 \%$ dan mempunyai nilai harapan sebesar 37.2, mayoritas responden mengalami penyakit DM selama < 5 tahun sebanyak $57.5 \%$ dan mempunyai nilai harapan sebesar 37.6, suku responden 99.2\% adalah Suku Jawa dengan nilai harapan sebesar 37.4 dan komplikasi yang paling banyak dialami adalah tidak mengalami komplikasi DM dan mempunyai nilai harapan sebesar 37.0. 
http://stikesyahoedsmg.ac.id/ojs/index.php/sjkp

Tabel 1

Distribusi Frekuensi Responden Berdasarkan Tabulasi Silang antara Karakteristik Responden dengan Nilai Harapan di Wilayah Kerja Puskesmas Kedungmundu Kota Semarang Tahun 2019 (n=127)

\begin{tabular}{|c|c|c|c|c|c|}
\hline No & Karakteristik & Frekuensi & Prosentase & $\begin{array}{l}\text { Nilai Mean } \\
\text { Harapan }\end{array}$ & Total \\
\hline \multirow[t]{4}{*}{1.} & Usia & & & & \\
\hline & a. 60-74 tahun & 117 & $92.1 \%$ & 37.5 & $117(100 \%)$ \\
\hline & b. 75-90 tahun & 10 & $7.9 \%$ & 36.1 & $10(100 \%)$ \\
\hline & c. $>90$ tahun & 0 & $0 \%$ & 0.0 & $0(0 \%)$ \\
\hline \multirow[t]{7}{*}{2.} & Pekerjaan & & & & \\
\hline & a. BuruhTani & 2 & $1.6 \%$ & 40.5 & $2(100 \%)$ \\
\hline & b. Pedagang & 14 & $11.0 \%$ & 38.5 & $14(100 \%)$ \\
\hline & c. Wiraswasta & 10 & $7.9 \%$ & 35.5 & $10(100 \%)$ \\
\hline & d. Ibu RumahTangga (IRT) & 65 & $51.2 \%$ & 37.2 & $65(100 \%)$ \\
\hline & e. Pensiunan & 21 & $16.5 \%$ & 37.5 & $21(100 \%)$ \\
\hline & f. Tidak bekerja & 15 & $11.8 \%$ & 37.7 & $15(100 \%)$ \\
\hline \multirow[t]{5}{*}{3.} & Pendidikan & & & & \\
\hline & a. Tidak sekolah & 30 & $23.6 \%$ & 36.3 & $30(100 \%)$ \\
\hline & b. Pendidikan rendah & 69 & $54.3 \%$ & 37.6 & $69(100 \%)$ \\
\hline & c. Pendidikan menengah (SMA) & 20 & $15.7 \%$ & 37.9 & $20(100 \%)$ \\
\hline & d. Pendidikan tinggi (D1-S2) & 8 & $6.4 \%$ & 38.7 & $8(100 \%)$ \\
\hline \multirow[t]{7}{*}{4.} & Agama & & & & \\
\hline & a. Islam & 111 & $87.4 \%$ & 37.4 & $111(100 \%)$ \\
\hline & b. Kristen Protestan & 10 & $7.9 \%$ & 37.1 & $10(100 \%)$ \\
\hline & c. Kristen Katolik & 6 & $4.7 \%$ & 37.2 & $6(100 \%)$ \\
\hline & d. Hindu & 0 & $0 \%$ & 0.0 & $0(0 \%)$ \\
\hline & e. Budha & 0 & $0 \%$ & 0.0 & $0(0 \%)$ \\
\hline & f. Kong Hu Chu & 0 & $0 \%$ & 0.0 & $0(0 \%)$ \\
\hline \multirow[t]{4}{*}{5.} & Status Perkawinan & & & & \\
\hline & a. Menikah & 75 & $59.1 \%$ & 38.0 & $75(100 \%)$ \\
\hline & b. Bercerai & 1 & $0.8 \%$ & 44.0 & $1(100 \%)$ \\
\hline & c. Cerai meninggal & 51 & $40.2 \%$ & 36.3 & $51(100 \%)$ \\
\hline \multirow[t]{3}{*}{6.} & Jenis Kelamin & & & & \\
\hline & a. Laki-laki & 35 & $27.6 \%$ & 37.9 & $35(100 \%)$ \\
\hline & b. Perempuan & 92 & $72.4 \%$ & 37.2 & $92(100 \%)$ \\
\hline \multirow[t]{5}{*}{7.} & Lama Sakit & & & & \\
\hline & a. $\leq 5$ tahun & 73 & $57.5 \%$ & 37.6 & $73(100 \%)$ \\
\hline & b. $\leq 10$ tahun & 23 & $18.1 \%$ & 35.9 & $23(100 \%)$ \\
\hline & c. $\leq 15$ tahun & 16 & $12.6 \%$ & 38.4 & $15(100 \%)$ \\
\hline & d. $>15$ tahun & 15 & $11.8 \%$ & 37.4 & $15(100 \%)$ \\
\hline \multirow[t]{3}{*}{8.} & Suku & & & & \\
\hline & a. Jawa & 126 & $99.2 \%$ & 37.4 & $126(100 \%)$ \\
\hline & b. Lainnya & 1 & $0.8 \%$ & 37.0 & $1(100 \%)$ \\
\hline \multirow[t]{10}{*}{9.} & Komplikasi & & & & \\
\hline & a. Retinopati & 12 & $9.4 \%$ & 38.0 & $12(100 \%)$ \\
\hline & b. Neuropati & 12 & $9.4 \%$ & 38.4 & $12(100 \%)$ \\
\hline & c. Nefropati & 7 & $6 \%$ & 37.5 & $7(100 \%)$ \\
\hline & d. Ulkus Kaki & 0 & $0 \%$ & 0.0 & $0(0 \%)$ \\
\hline & e. Amputasi & 1 & $0.8 \%$ & 37.0 & $1(100 \%)$ \\
\hline & f. GagalJantung & 10 & $7.9 \%$ & 38.9 & $10(100 \%)$ \\
\hline & g. Stroke & 6 & $4.7 \%$ & 37.2 & $6(100 \%)$ \\
\hline & h. Hipertensi & 21 & $16.5 \%$ & 36.8 & $21(100 \%)$ \\
\hline & i. Tidakada & 58 & $45.7 \%$ & 37.0 & $58(100 \%)$ \\
\hline
\end{tabular}


Tabel 2

Distribusi Frekuensi JawabanTiap Item Pernyataan Harapan Lansia dengan Diabetes MelitusTipe 2 di Wilayah Kerja Puskesmas Kedungmundu Kota Semarang Tahun 2019 (n=127)

\begin{tabular}{|c|c|c|c|c|c|c|}
\hline No. & Item Pertanyaan & $\begin{array}{l}\text { STS } \\
\text { (\%) }\end{array}$ & $\begin{array}{l}\text { TS } \\
(\%)\end{array}$ & $\begin{array}{l}\mathrm{S} \\
(\%)\end{array}$ & $\begin{array}{l}\text { SS } \\
(\%)\end{array}$ & Mean \\
\hline \multicolumn{7}{|c|}{ Komponen temporality and future } \\
\hline 1. & $\begin{array}{l}\text { Saya mempunyai pandangan positif terhadap } \\
\text { kehidupan }\end{array}$ & $0 \%$ & $2.4 \%$ & $80.3 \%$ & $17.3 \%$ & 3.15 \\
\hline 2. & $\begin{array}{l}\text { Saya mempunyai tujuan jangka pendek dan / } \\
\text { atau jangka panjang. }\end{array}$ & $0 \%$ & $7.1 \%$ & $82.7 \%$ & $10.2 \%$ & 3.03 \\
\hline 6. & Saya merasa takut dengan masa depan saya. & $25.2 \%$ & $60.6 \%$ & $11.0 \%$ & $3.1 \%$ & 3.08 \\
\hline 11. & $\begin{array}{l}\text { Saya percaya bahwa setiap hari memiliki } \\
\text { potensi masing-masing. }\end{array}$ & $0 \%$ & $5.5 \%$ & $76.4 \%$ & $18.1 \%$ & 3.13 \\
\hline \multicolumn{7}{|c|}{ Komponen positive readiness and expectancy } \\
\hline 4. & $\begin{array}{l}\text { Saya dapat melihat berbagai kemungkinan di } \\
\text { tengah-tengah kesulitan. }\end{array}$ & $0 \%$ & $19.7 \%$ & $70.9 \%$ & $9.4 \%$ & 2.90 \\
\hline 7. & $\begin{array}{l}\text { Saya dapat mengingat saat-saat yang } \\
\text { membahagiakan / menyenangkan }\end{array}$ & $0 \%$ & $9.4 \%$ & $65.4 \%$ & $25.2 \%$ & 3.16 \\
\hline 10. & $\begin{array}{l}\text { Saya memiliki gagasan yang jelas tentang apa } \\
\text { yang ingin saya lakukan atau capai. }\end{array}$ & $0.8 \%$ & $13.4 \%$ & $75.6 \%$ & $10.2 \%$ & 2.95 \\
\hline 12. & $\begin{array}{l}\text { Saya merasa hidup saya memiliki nilai dan } \\
\text { berharga. }\end{array}$ & $0 \%$ & $2.4 \%$ & $55.1 \%$ & $42.5 \%$ & 3.40 \\
\hline \multicolumn{7}{|c|}{ Komponen interconnectedness } \\
\hline 3. & Saya merasa sendirian & $19.7 \%$ & $53.5 \%$ & $25.2 \%$ & $1.6 \%$ & 2.91 \\
\hline 5. & $\begin{array}{l}\text { Saya memiliki keyakinan/keimanan yang } \\
\text { memberi saya kenyamanan }\end{array}$ & $0 \%$ & $0.8 \%$ & $66.1 \%$ & $33.1 \%$ & 3.32 \\
\hline 8. & Saya memiliki kekuatan batin dalam diri saya. & $0 \%$ & $11.8 \%$ & $69.3 \%$ & $18.9 \%$ & 3.07 \\
\hline 9. & $\begin{array}{l}\text { Saya mampu untuk memberi dan menerima } \\
\text { perhatian / cinta }\end{array}$ & $0 \%$ & $4.7 \%$ & $59.8 \%$ & $35.4 \%$ & 3.31 \\
\hline \multicolumn{6}{|c|}{ Total Nilai Harapan } & 37.41 \\
\hline
\end{tabular}

Tabel 2 menunjukkan bahwa sebanyak 80.3\% lansia masih mempunyai pandangan positif terhadap kehidupannya. Selain itu, sebanyak 53.5\% lansia tidak setuju dengan pernyataan bahwa dirinya merasa sendirian. Mayoritas lansia menganggap hidupnya bernilai dan berharga yaitu sebanyak $55.1 \%$ setujudan $42.5 \%$ sangat setuju, namun terdapat $2.4 \%$ yang tidak setuju dengan pernyataan tersebut. Selain itu terdapat $11.0 \%$ lansia yang merasa takut dengan masa depannya. Jika dilihat dari skor total nilai mean maka nilai harapan lansia dengan DM tipe 2 pada penelitian ini adalah sebesar 37.41. Jika dilihat pada klasifikasi derajat harapan, maka nilai ini menunjukkan derajat harapan yang tinggi.

\section{PEMBAHASAN}

Hasil penelitian berdasarkan tabel 1 menunjukkan bahwa mayoritas responden berusia 60-74 tahun yaitu berjumlah 117 orang (92.1\%). Jika dilihat dari nilai harapan, maka lansia dengan usia 60-74 tahun memiliki nilai harapan yang lebih besar daripada yang berusia 75-90 tahun. Hal ini sesuai dengan penelitian Wendy pada pasien kanker dimana semakin tua usia maka harapan akan semakin turun (Duggleby, 2013). Menurut Siezacova bahwa semakin tua usia maka harapan akan semakin menurun berkaitan dengan tantangan baik dari segi kesehatan, kemampuan intelektual dan psikologi akibat kehilangan pekerjaan maupun ditinggalkan oleh pasangan (Siezacova, 2017).

Mayoritas pekerjaan responden adalah ibu rumah tangga (IRT) (51.2\%) hal ini dapat berkaitan dengan jenis kelamin responden yang 
$72.4 \%$ adalah perempuan. Jika dilihat dari nilai harapan, maka responden yang bekerja (buruh tani, pedagang dan wiraswasta) memiliki total nilai harapan yang lebih tinggi daripada yang tidak bekerja (IRT, pensiunan dan tidak bekerja) yaitu 38.1>37.4). Herth mengemukakan jika pekerjaan dapat menentukan tingkat harapan dimana pekerjaan dengan pendapatan cukup mempunyai harapan yang lebih tinggi daripada pendapatan kurang atau tidak bekerja (Herth, 1992).

Pendidikan responden didominasi oleh pendidikan rendah atau lulusan SD-SMP (54.3\%). Oliveira (2018) dalam penelitiannya juga menyebutkan bahwa pendidikan responden didominasi oleh lulusan SD (38.4\%) (Oliveira, 2018). Pada tabel 1 jika dilihat pada nilai harapannya, maka nilai harapan akan semakin naik seiring dengan tingkat pendidikan yang semakin tinggi. Lesak dalam Siezacova (2017) menyebutkan jika responden dengan pendidikan SD mempunyai nilai harapan yang lebih rendah daripada pendidikan SMA dan universitas (Siezacova, 2017). Menurut Wahyuni (2014), responden dengan pendidikan tinggi akan lebih banyak mencari tahu mengenai info kesehatan dan manajemen penyakit sehingga mempunyai pengetahuan yang lebih luas dan berdampak pada manajemen penyakit serta meminimalisir timbulnya komplikasi sehingga harapan akan terjaga (Wahyuni, 2014).

Agama responden didominasi oleh agama Islam (87.4\%). Nilai harapan responden yang beragama Islam adalah 37.4 menunjukkan harapan yang tinggi. Hal ini sesuai dengan penelitian Souza et al bahwa harapan memiliki hubungan yang erat dengan spritualitas (Souza et al, 2017).Depresi mempunyai korelasi negatif dengan harapan sehingga semakin rendah tingkat depresi maka harapan akan semakin tinggi. Status perkawinan responden sebagian besar adalah menikah (59.1\%) dan memiliki harapan sebesar 38.0 .

Nilai harapan ini lebih besar daripada status perkawinan cerai meninggal. Hal ini sejalan dengan penelitian pada pasien dengan penyakit jantung yang dilakukan oleh Tobin dkk (2016) dan pasien yang menjalani hemodialisa (HD) yang dilakukan oleh dimana tingkat harapan akan lebih tinggi pada responden yang menikah dan mempunyai pasangan daripada yang cerai atau cerai meninggal. Menurut Tobin hadirnya pasangan mampu memberikan perasaan nyaman, dukungan dan kasih sayang sehingga meningkatkan harapan akan masa depan (Tobin et al, 2016).

Jenis kelamin responden didominasi oleh perempuan (72.4\%). Hal ini sesuai dengan teori Fowles \& Greenberg serta Kuchemann bahwa perempuan mempunyai usia lebih panjang 6-8 tahun daripada pasangannya. Oliveira (2018) pada penelitianya juga menemukan bahwa jenis kelamin responden didominasi oleh perempuan (86.5\%)(Oliveira, 2018). Hal ini juga sesuai dengan data Riskesdas bahwa penderita DM lebih tinggi pada wanita (Kemenkes RI, 2014). Jika dilihat pada nilai harapan, maka laki-laki mempunyai nilai harapan yang lebih besar daripada perempuan.

Hal ini sesuai dengan penelitian sebelumnya pada pasien dengan penyakit kronis yang dilakukan oleh Bednaricova dalam Siezacova (2017) dan Duggleby (2013) bahwa nilai harapan lebih tinggi pada responden lakilaki. Menurut Visser dalam Siezacova (2017) bahwa perempuan lebih mudah mengalami depressive symptoms atau tanda gejala depresi daripada laki-laki sehingga menurunkan derajat harapannya (Siezacova, 2017).

Lama sakit responden didominasi oleh lama sakit $<5$ tahun (57.5\%). Hasil ini sejalan dengan penelitian Siwiutami (2017) bahwa mayoritas responden DM mempunyai lama sakit $<5$ tahun (Siwiutami, 2017). Nilai harapan pada lansia dengan DM tipe 2 paling tinggi dimiliki oleh kelompok lama sakit antara 10-15 tahun sebesar 38.4. Menurut Sharoni \& Wu bahwa penderita DM dengan durasi lebih lama memiliki efikasi diri yang baik karena lebih 
berpengalaman dalam pengelolaan penyakit (Sharoni, S. K .A. \& Wu, S. F. V., 2012). Suku responden didominasi oleh Suku Jawa (99.2\%) hal ini dikarenakan penelitian dilakukan pada masyarakat yang tinggal di wilayah Suku Jawa. Nilai harapan responden berdasarkan suku adalah 37.4 yang menunjukkan harapan tinggi.

Komplikasi responden didominasi oleh hipertensi (16.5\%) namun angka responden yang tidak mengalami komplikasi justru lebih besar (45.7\%). Hasil ini sejalan dengan penelitian Siwiutami mengenai kualitas hidup pasien DM dimana pada karakteristik komplikasi didominasi oleh responden yang tidak mengalami komplikasi (48.4\%) (Siwiutami, 2017). Tingginya angka responden yang tidak mengalami komplikasi dapat dihubungkan dengan lama sakit responden yang didominasi oleh lama sakit $<5$ tahun. Selain itu kepatuhan diet dan manajemen yang baik juga dapat meminimalisir munculnya komplikasi (Risnasari, 2014). Nilai harapan pada responden dengan komplikasi hipertensi adalah 36.8 merupakan nilai terendah diantara semua komplikasi.

Hasil penelitian mengenai gambaran harapan pada lansia dengan DM tipe 2 berdasarkan tabel 2 menunjukkan nilai mean harapan adalah sebesar 37.41 menunjukkan derajat harapan yang tinggi. Penelitian yang mendukung adalah penelitian Ottaviani(2014) pada pasien chronic kidney disease (CKD) yang menunjukkan derajat harapan tinggi dengan nilai mean 38.06 (Ottaviani, 2014). Faktor demografi yang mendukung tingkat harapan responden berada pada tingkat yang tinggi diantaranya adalah tingginya jumlah responden yang menikah, lama sakit dan komplikasi.

Hasil penelitian ini tidak sejalan dengan penelitian Orlandi (2012) pada klien yang mengalami CKD dengan kesimpulan bahwa derajat harapannya adalah sedang (36.20) (Orlandi, 2012). Oliveira (2018) dalam penelitiannya menyatakan jika harapan pada lansia dengan penyakit kronis adalah sedang (35.88) (Oliveira, 2018). Hasil penelitian ini juga berbeda dengan penelitian pada pasien dengan
CKD yang menjalani hemodialisa dimana tingkat harapannya adalah rendah (Orlandi, 2012). Hasil yang berbeda-beda mengenai harapan menunjukkan jika harapan bergantung pada derajat kesehatan, koping terhadap penyakit dan self esteem yang akan meningkatkan persepsi tentang harapan (Oliveira, 2018).

Item pernyataan dengan nilai mean tertinggi adalah pernyataan nomer 12 "saya merasa hidup saya bernilai dan berharga". Hal ini menunjukkan jika lansia dengan DM tipe 2 tidak merasa putus asa terhadap hidupnya dan merasa bahwa hidup yang dijalaninya berharga. Pernyataan lain yang menduduki peringkat kedua tertinggi adalah pernyataan nomer 9 yaitu "saya mampu untuk memberi dan menerima perhatian/cinta". Hal ini dapat dikaitkan dengan karakteristik responden yang didominasi oleh status perkawinan menikah.

Pernyataan yang mempunyai nilai mean terendah adalah pernyataan nomer 4 "saya dapat melihat kemungkinan ditengah-tengah kesulitan". Pernyataan ini merupakan representasi dari komponen harapan affectivebehavioral sehingga nilai yang rendah mengindikasikan ketidakmampuan untuk mengatasi dan beradaptasi terhadap keinginan personal dan melakukan kegiatan yang dapat meningkatkan kesehatan.

\section{KESIMPULAN}

Harapan lansia dengan DM tipe 2 mempunyai nilai rata-rata 37.41 menunjukkan harapan tinggi. Diharapkan lansia dapat meningkatkan harapannya terutama dalam hal sosialisasi baik dengan keluarga maupun lingkungan sekitar. Peneliti juga menyarankan agar perawat yang berada di puskesmas mampu melakukan pengkajian mengenai derajat harapan pada lansia dengan penyakit kronis tidak hanya DM saja. Perawat dapat membantu lansia dalam meningkatkan kemampuan bersosialisasi dan menghadirkan dukungan sosial bagi lansia untuk dapat mempertahankan harapannya. 


\section{REFERENSI}

Dinas Kesehatan Kota Semarang.(2018). Profil Kesehatan Kota Semarang 2017.Semarang :Dinas Kesehatan Kota Semarang.

Duggleby W. et al, (2013). Hope in Newly Diagnosed Cancer Patients. 5, Canada : Journal of Pain and Symptom Management, Vol. 46. 0885-3924

HaristaArief, dkk. (2015). Depresi pada Penderita Diabetes Mellitus Tipe 2.Fakultas Kedokteran Lampung, Vol.4 No.9

Herth, Kaye. (1992). Abbreviated Instrument to Measure Hope: Development and Psychometric Evaluation. USA : Journal of advanced Nursing, 1992, Vol. 17.

International Diabetes Federation (IDF).(2017). Diabetes Atlas Eight Edition 2017.Federation, International Diabetes.Belgium :www.diabetesatlas. 0 $\mathrm{rg}$

Kementrian Kesehatan RI. (2014). Infodatin Situasi dan Analisis Diabetes. Jakarta :Pusat Data dan Informasi Kementrian Kesehatan RI

Matzinger M., Katrin Fischuber, Elke H. Heiss. (2017). Activation of Nrf2 Signalingby Natural Products Can it Alleviate Diabetes?Vienna, Austria: Biotechnology Advances.

Mauk, Kristen L., Nola K.Schmidt. (2004). Spiritual Care Nursing Practice.USA: Library of Congress Catalogue, 0-78174096-7

Oliveira LM,et al. (2018). The Life Hope of Elderly: Profile assessment and Herth Scale. Brazil: Cuidado E Fundamental. Vol 10 (1)

Orlandi, Fabiana de Sauza,etal. (2012). The Evaluation of the level of Hope of Elderly with Chronic Kidney Disease patients undergoing Hemodialysis, Ref esc enferm USP, pp. 897-902
Ottaviani, et al. (2014).Hope and Spirituality Among Patients with Chronic Kidney Disease Undergoing Hemodialysis: a Correctional Study. ev. Latinoam.Enfermagem Vol. 2 Iss. 2

Risnasari, N. (2014). Hubungan Tingkat Kepatuhan Diet Pasien Diabetes Melitus dengan Munculnya Komplikasi di Puskesmas Pesantren Kota Kediri, No. 25.

Siezacova, Alena.(2017). Hope and Well-Being Psychological Correlates and enefits.Czech Republic: Fourth Monograph in Resilience and Health by the Centre for Resilience and SocioEmotional Health, University of Malta

Siwiutami, Fitria. (2017). Gambaran Kualitas Hidup pada Penyandang Diabetes Melitus Wilayah Puskesmas Purwosari Surakarta

Souza, Érica Nestor, Oliveira, Nathalia Alves de, Luchesi, BrunaMoretti, Gratão, Aline Cristina Martins, Orlandi, Fabiana de Souza, \&Pavarini, Sofia Cristina lost. (2017). Relationship between hope and spirituality of elderly caregivers. Texto\&Contexto Enfermagem

Sharoni, S. K .A. \& Wu, S. F. V. 2012. Selfefficacy and self-care behavior of Malaysian patients with type 2 diabetes a cross sectional survey. Nursing and Health Sciences, 14, 38-45. doi: 10.1111/j.1442-2018.2011.00658.x

Tobin, Alice Mary Kelly. (2016). Hope and Health Related Quality of Life of Older Women Who Have Had Heart Attacks. New York : Academic Works

Wahyuni, Yuli. (2014). Kualitas Hidup berdasarkan Karakteristik Pasien DM Tipe 2. Jurnal Universitas Padjadjaran Vol. 2 Nomor 1 